\title{
Moda plus size no contexto da racionalidade neoliberal: empoderamento, gerenciamento de si e consumo
}

Plus size fashion in the context of neoliberal rationality: empowerment, self-management and consumption

Resenha de: AIRES, Aliana: De gorda a plus size: a moda do tamanho grande. Barueri: Editora Estação das Letras e Cores, 2019.

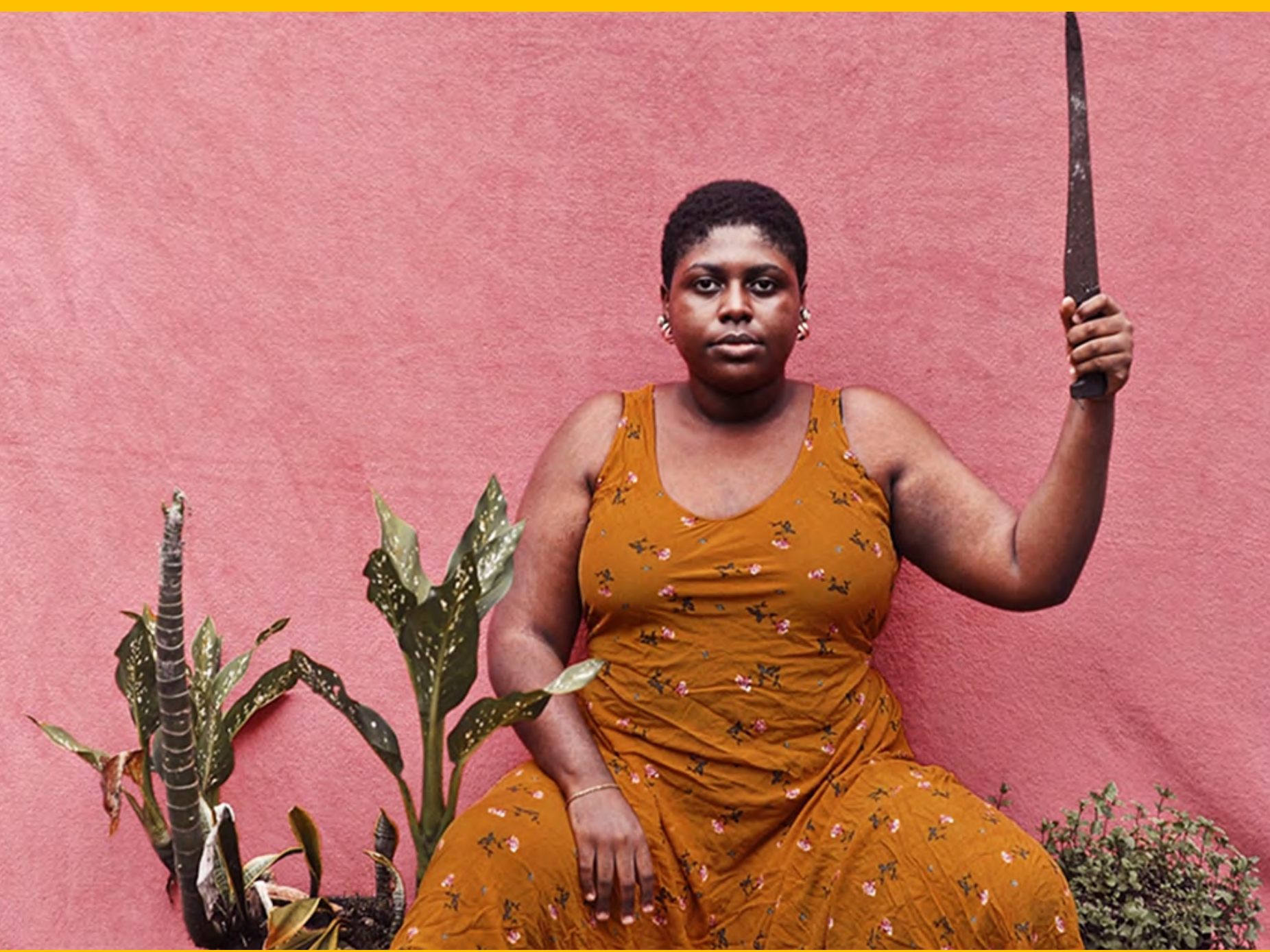


Ana Lucia de Castro ${ }^{1}$

ORCID: https://orcid.org/0000-0002-6165-7722

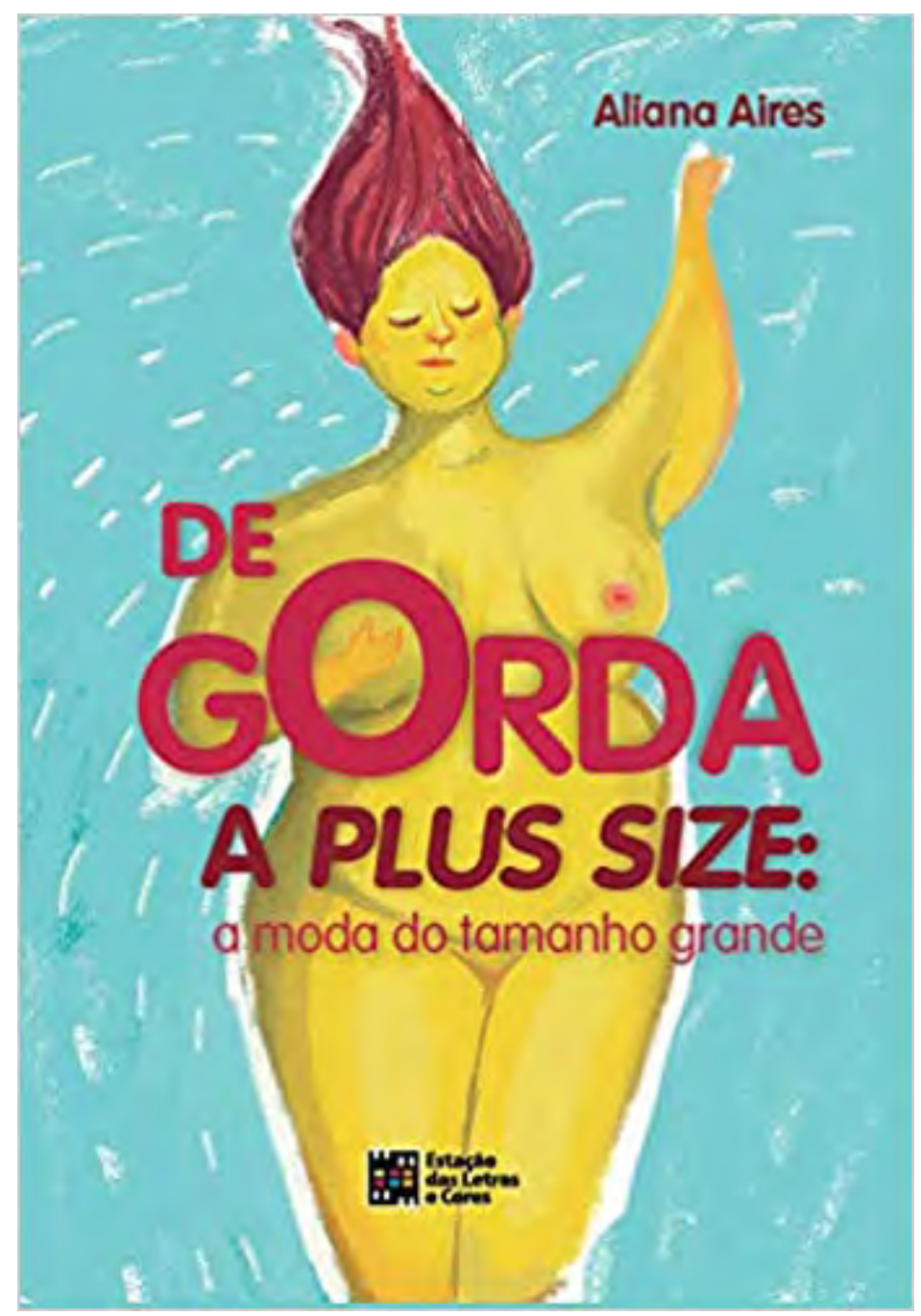

O livro de Aliana Aires consiste em uma excelente reconstituição histórica da produção e do consumo de moda para tamanhos grandes, colocando em perspectiva comparativa as sociedades americana e brasileira. Fruto de pesquisa multidisciplinar, realizada para fins

\footnotetext{
1 Professora Livre-Docente do Departamento de Ciências Sociais e do Programa de Pós-Graduação em Ciências Sociais da Universidade Estadual Paulista (Unesp/Campus Araraquara). E-mail: ana.castro@ unesp.br. Lattes: http://lattes.cnpq.br/7666683358005843.
} 
de doutoramento, o trabalho opera com referências de diversas áreas de estudo (Moda, Sociologia, Antropologia, Comunicação), mobilizando autores de campos de reflexão variados. A autora realiza rigorosa e extensa pesquisa documental em peças publicitárias de moda, veiculadas no Brasil e nos EUA durante todo o século XX e meados do XXI, demonstrando as mudanças nas concepções e práticas que circundam o corpo gordo, apresentando-o como objeto de julgamentos e classificações e, simultaneamente, de estratégias classificatórias de posições sociais e prestígio, como colocaria Pierre Bourdieu (2007). Para este autor, a distinção social passa pela habilidade em operar eficazmente os sistemas classificatórios que permitem aos indivíduos e aos grupos participarem do jogo de disputas por poder e prestígio social. Nesse jogo, os cuidados com a apresentação corporal, ao lado do consumo cultural e alimentar seriam, na visão do autor, as três mais importantes formas de se distinguir.

A obra nos traz um amplo mapeamento histórico dos sentidos vinculados ao corpo gordo, situando as mudanças de concepção, verificadas ao longo da história, na definição de obesidade e de gordura corporal. Demonstra, com maestria, a maneira como os significados atribuídos ao corpo considerado gordo passaram por alterações desde o início do século $\mathrm{XX}$, quando o excesso de peso, expresso nas formas mais volumosas era, em alguns casos, associado ao padrão de beleza vigente e revestido de positividade, representando saúde e vitalidade. A partir dos anos 1950, no entanto, os significados atribuídos ao corpo gordo começam a ser, cada vez mais, associados à ideia de obesidade, patologia, negligência, enquanto o padrão de beleza socialmente estabelecido preconiza o corpo magro, esbelto.

Em seu perspicaz movimento reflexivo, a autora mobiliza diferentes fontes de dados, não desprezando as narrativas e as percepções correntes na cultura popular e que irrigam o imaginário, construindo uma perspectiva analítica comparativa entre Brasil e Estados Unidos, país pioneiro em desenvolver tanto um mercado de moda plus size como movimentos ativistas em defesa do direito de ter um corpo considerado gordo ou acima do peso ideal.

0 refinamento da análise não exclui as ambiguidades que as mensagens circulantes sempre comportam. Como demonstra Aliana Aires, a valorização do corpo magro hoje vigente foi sendo lentamente construída desde o início do século XX, associada à modernidade capitalista, e, nesse processo, é possível observarmos a concomitância - à essa tendência de valorização da magreza - de discursos por vezes dissonantes, como o da associação da magreza a atributos negativos, presentes na publicidade de produtos para ganhar peso e ter um aspecto melhor, ou na expressão magra de ruim ou, ainda, narrativas relativas à positivação de formas mais avolumadas, como é o caso das imagens de pin-ups difundidas entre os soldados norte-americanos durante a segunda guerra.

Ao buscar contextualizar os anúncios analisados à época de sua veiculação, a autora articula vários processos e instâncias, como a difusão do discurso médico sobre a obesidade, o desenvolvimento da produção e do consumo de moda em padronagens plus size e a emergência do ativismo pró-positivação do corpo gordo, elaborando uma densa perspectiva historiográfica que não descuida das mediações entre mídia e sociedade.

Em sua reflexão sobre a publicidade como mecanismo midiático que veicula os discursos sobre obesidade, positivando ou negativizando o corpo gordo, a perspectiva desenvolvida é claramente preocupada com as mediações entre mídia e sociedade. 0 questionamento sobre a mídia, em uma visão analítica apoiada na teoria das mediações, consiste em 
um desafio na maioria das vezes de difícil superação, uma vez que a tendência é a análise situar-se no conteúdo das mensagens em si, sem articulações com os contextos de enunciação e os públicos receptores. A proposta da teoria das mediações (MARTíN-BARBERO, 1997; CANCLINI, 1997; THOMPSON, 1995) pressupõe uma relação de mão dupla entre os polos da produção e da recepção das informações midiáticas, na qual os conteúdos veiculados dialogam diretamente com o cotidiano dos expectadores/leitores, que os (re)significam a partir de suas experiências e repertórios. Em consonância com a teoria das mediações, John Thompson (1995) afirma a necessidade de estar atento aos contextos sociais em que os discursos são recebidos. Qualquer reflexão sobre a recepção das mensagens da mídia deve entendê-la como um processo contínuo e socialmente diferenciado, "que depende do conteúdo das mensagens recebidas, da elaboração discursiva das mensagens entre os receptores e os outros e dos atributos sociais dos indivíduos que as recebem" (THOMPSON, 1995, p. 201).

A mesma perspicácia analítica pode ser verificada no tratamento destinado à esfera do consumo na discussão do tema. Enfatizando que o termo plus size nasce no mercado de moda como estratégia publicitária, a autora demonstra sua apropriação por movimentos sociais e ativistas que reivindicam a diversidade de corpos e o direito a ser gordo sem sofrer estigmatizações ou censuras impostas pelo discurso médico e normatizador e, nesse sentido, aponta o empoderamento que o termo propiciou, sobretudo às mulheres classificadas como obesas ou acima do peso.

Como nos lembra Mary Douglas e Baron Isherwood (2004), como prática cultural, o consumo organiza e classifica o mundo à nossa volta. Para além de simples compra e descarte dos produtos, permite o estabelecimento de relações sociais, fortalecendo vínculos ou distinções entre indivíduos e grupos, classificando-os, ao indicar posições sociais e expressar prestígio. Como espécie de cimento social, o consumo propicia a circulação de significados simbólicos, reafirmando ou negando discursos e práticas. Nesse sentido, Aliana Aires analisa a maneira como a visibilização do consumo de moda plus size colocou em circulação imagens de moda para corpos maiores, positivando-os e interferindo nas representações corporais vigentes, além de levar as mulheres gordas a experimentarem mudanças na construção identitária, na autoestima, no pertencimento social e nas sociabilidades.

Entretanto, como ocorre, em geral, com todos os discursos que propõem comportamentos não contemplados pelo hegemonicamente estabelecido, tal movimento de empoderamento foi cooptado pelo mercado, que se apropriou dessa busca de reconhecimento da diferença, ressignificando-a. Além disso, como bem salienta a autora, esse fenômeno também atua como estratégia biopolítica uma vez que estende normatizações de formas de vida e de relacionamento com o próprio corpo e anteriormente não extensivos às mulheres gordas. Nas palavras de Aliana:

O fortalecimento do mercado plus size no mundo todo evidencia a intensificação e sofisticação do investimento do biopoder que amplia sua abrangência sobre a população, expandindo suas fronteiras para abrigar segmentos populacionais que passavam ao largo de sua ação ou sofisticando suas estratégias de ação sobre a população. (AIRES, 2019, p. 141) 
Dessa forma, a pesquisadora elucida a maneira como a inclusão do corpo gordo ocorre apenas no âmbito da moda e do consumo, propiciando a inserção somente na condição de consumidoras, permanecendo a exclusão de outros âmbitos da vida social. Como sentencia a autora: "A moda para tamanhos grandes transforma as mulheres em consumidoras, não em cidadãs" (AIRES, 2019, p. 129).

A ampliação do poder de compra, longe de estabelecer formas mais democráticas de vida, atualiza novos modos de dominação e exclusão. A intensificação dos traços de uma cultura de consumo, que organiza o universo dos bens segundo os princípios de sedução e efemeridade, acarreta, como um dos seus desdobramentos, a produção de uma subjetividade empreendedora e mercantilizada, em sintonia com os pressupostos de uma racionalidade global neoliberal, ou com a nova razão do mundo, como denominam Pierre Dardot e Christian Laval (2016). Nesse contexto, o corpo se configura como um recurso estratégico que o sujeito é impelido a gerir eficientemente, e a noção de management emerge como uma categoria que excede o âmbito do mundo do trabalho ao espraiar-se pelo tecido cultural, articulando amplo espectro de práticas sociais, culturais e corporais.

Enfim, sem desconsiderar o empoderamento das mulheres gordas - decorrente da visibilidade e da positivação de seus corpos promovidos pela publicidade da moda plus size -, o trabalho de Aliana Aires contribui para a compreensão da articulação entre a expansão desse segmento do mercado de consumo de moda e a tendência ao empresariamento de si, elemento central na configuração da fábrica do sujeito neoliberal (DARDOT; LAVAL, 2016). Trata-se, portanto, de leitura fundamental para os interessados em compreender as articulações entre mídia, moda e mercado no interior da lógica cultural hegemônica que marca a contemporaneidade.

\section{Referências}

BOURDIEU, Pierre. A distinção: crítica social do julgamento. São Paulo: Edusp/ Porto Alegre: Zouk, 2007.

CANCLINI, Néstor. Garcia Culturas híbridas. São Paulo: Edusp, 1997.

DARDOT, Pierre.; LAVAL, Christian. A nova razão do mundo: ensaio sobre a sociedade neoliberal. São Paulo: Boitempo Editorial, 2016.

DOUGLAS, Mary.; ISHERWOOD, Baron. 0 mundo dos bens: para uma antropologia do consumo. Rio de Janeiro: Ed. UFRJ, 2004.

MARTÍN-BARBERO, Jésus. Dos meios às mediações: comunicação, cultura e hegemonia. Rio de Janeiro: Ed. UFRJ, 1997.

THOMPSON, John Brookshire. Ideologia e cultura moderna: teoria social crítica na era dos meios de comunicação de massa. Petrópolis: Vozes, 1995. 